\title{
Mean and variance evolutions of the hot and cold temperatures in Europe
}

\author{
S. Parey ${ }^{2}$, D. Dacunha-Castelle ${ }^{1}$, T.T.Huong Hoang ${ }^{1,2}$, \\ [1] Laboratoire de Mathématiques, Université Paris 11, Orsay, France \\ [2] EDF/R\&D, 6 quai Watier, 78401 Chatou Cedex, France
}

\author{
Tel : 33130877614 \\ Fax : 33130877108 \\ sylvie.parey@edf.fr
}

\begin{abstract}
In this paper, we examine the trends of temperature series in Europe, for the mean as well as for the variance in hot and cold seasons. To do so, we use as long and homogenous series as possible, provided by the European Climate Assessment and Dataset project (ECA\&D) for different locations in Europe, as well as the European ENSEMBLES project gridded dataset and the ERA40 reanalysis. We provide a definition of trends that we keep as intrinsic as possible and apply non parametric statistical methods to analyze them. Obtained results show a clear link between trends in mean and variance of the whole series of hot or cold temperatures: in general, variance increases when the absolute value of temperature increases, i.e. with increasing summer temperature and decreasing winter temperature. This link is reinforced in locations where winter and summer climate has more variability. In very cold or very warm climates, the variability is lower and the link between the trends is weaker. We performed the same analysis on outputs of six climate models proposed by European teams for the 1961-2000 period (1950-2000 for one model), available through the PCMDI portal for the IPCC fourth assessment climate model simulations. The models generally perform poorly and have difficulties in capturing the relation between the two trends, especially in summer.
\end{abstract}

Keywords: non parametric trends; mean and variance; temperature

\section{Introduction}

Global and regional warming is observed and is now well established for the $20^{\text {th }}$ century, at least for the mean temperature. This temperature increase is bound to continue, and changes in mean temperature as well as in variability and extremes are predicted. These have important implications in terms of adaptation. Katz et al., 1992, have already mentioned that the variability change has more impact on extremes than the change in the mean. Some authors have also looked at the impact of climate change on both mean and variability. Schär et al., 2004, pointed out the role of increasing variability in the occurrence of the 2003 heat wave in 
Europe. Ferro et al., 2005, proposed a technique to explore changes in probability distributions and applied it to climate model simulations. Here, we would like to focus on observed datasets, in order to carefully study the observed properties of the mean and variance of temperature series, before investigating climate model simulations. As a matter of fact, climate models are designed to represent and simulate the possible evolution of global and regional mean temperature, but their ability to reproduce observed trends, variability and extremes, at least at local scales where they influence industrial activities, is not yet fully demonstrated. Therefore, a careful study of the link between trends in mean and variance of daily minimum and maximum temperature, is a first step to analyse in detail the relationships between these trends and the trends in extremes. In this context, we focused on daily maximum summer temperatures and daily minimum winter temperatures. To do so, we used 55 as long and homogeneous temperature series as possible, for Europe. Those were obtained from the European Climate Assessment and Dataset project (ECA\&D) (Klein et al., 2002). The study has then been conducted using the ENSEMBLES project gridded dataset (Haylock et al., 2007) and the ERA40 reanalysis. Trend identification is carried out using non parametric methods, in order to avoid any assumption on the shape of trends. Then, the same analysis is performed using the results of six climate models proposed by European teams for the period 1961-2000 (1950-2000 for 1 model), obtained in the framework of the fourth IPCC assessment report and made available through the PCMDI portal.

The paper is organised as follows: section 2 presents the temperature series used, then section 3 describes the general statistical methods of smoothing which are used for all series in this paper, for the mean as well as for the variance. In section 4 we discuss the results obtained from the different observed datasets. Section 5 gives the results obtained from the climate simulation models, before concluding in section 6.

\section{Presentation of the used data series}

\subsection{ECA\&D series}

The initial temperature series used in this study consist of 55 of the longest and most homogeneous daily minimum and maximum temperature series made 
available by the European Climate Assessment and Dataset project (ECA\&D) (Klein et al., 2002). For each of the collected series, the ECA\&D project tested for homogeneity using different test to identify breaks. The results are summarised for each series over different periods in classifying it as "suspect", "useful" or "undetermined" and in indicating the years when breaks have been identified. In the first place, only series quoted as "useful" over the 1946-2006 and the 19012006 periods have been retained. Then, among these series we keep only those for which no break has been identified with the 3 methods used in the ECA\&D project. Table 1 summarises the series and their period lengths whereas figure 1 shows their geographical location in Europe. The period lengths are the maximum periods of available (non missing) data since 1946 (for 53 series) or 1901 (for the 2 Deols and Dresden series "useful" over this period).

\subsection{European ENSEMBLES project gridded dataset}

The production of gridded daily datasets from observations is one of the deliverables of the European ENSEMBLES project (www.ensembles-eu.org): the research team RT5.1 of the project is due to produce observational daily gridded datasets for temperature and precipitations. The ENSEMBLES project is supported by the European Commission's 6th Framework Programme as a 5 year Integrated Project from 2004 to 2009 under the Thematic Sub-Priority "Global Change and Ecosystems". Different datasets are now available, for daily minimum, maximum and mean temperature and daily precipitation amount, covering the period from 1950 to 2006 on a 0.25 and 0.5 degree regular grid as well as on a 0.22 and 0.44 degree rotated pole grid. The datasets for daily minimum (Tn) and daily maximum (Tx) temperature on a 0.5 degree regular grid have been used in this study.

\subsection{ERA40 reanalysis}

The European Centre for Medium range Weather Forecasts (ECMWF: www.ecmwf.int) has conducted a reanalysis project, in order to promote the use of global analyses of the state of the atmosphere, land and surface conditions over the period from mid 1957 to 2001 . The three dimensional variational technique has been applied using the T159L60 version of the Integrated Forecasting System to produce the analyses every six hours. The 2-meter temperature dataset over a 
2.5 degree regular grid has been used in this study. From this dataset, the maximum (minimum) of the 4 daily values has been considered for the daily temperature maximum (minimum). This leads to slightly under-estimated values compared to the "true" daily maximum or minimum, but with a comparable order of magnitude.

From these different datasets, the analysis has been made on a spatial window covering Europe between longitudes 10 and 65 East and between latitudes 35 and 80 North. The hot season has been defined as the 100 days between the $14^{\text {th }}$ of June and the $21^{\text {st }}$ of September, whereas the cold season has been defined as the 90 days between the $1^{\text {st }}$ of December and the $28^{\text {th }}$ of February. These periods have been selected because most extreme events occur between these dates. Daily maximum and minimum temperature have been considered in the hot and cold season respectively.

\section{Statistical tools}

\subsection{Trend definition}

If $\mathrm{X}(\mathrm{t})$ is the observation series whose mean and variance are respectively $\mathrm{m}(\mathrm{t})$ and $\mathrm{s}^{2}(\mathrm{t}), \mathrm{X}(\mathrm{t})$ can be expressed as $\mathrm{X}(\mathrm{t})=\mathrm{m}(\mathrm{t})+\mathrm{s}(\mathrm{t}) \mathrm{Y}(\mathrm{t})$, with $\mathrm{Y}(\mathrm{t})$ centred at 0 having variance 1 . $\mathrm{Y}(\mathrm{t})$ can be a stationary process or not, in particular its probability density function $\mathrm{g}(\mathrm{t}, \mathrm{x})$ can evolve with time $\mathrm{t}$ or not. For instance, the third moment or the distribution of extremes can depend on $t$ (see appendix for more details). However $\mathrm{m}(\mathrm{t})$ and $\mathrm{s}^{2}(\mathrm{t})$ are the usual or central trends of $\mathrm{X}(\mathrm{t})$. It can be proved that the different methods of estimation discussed below are valid even if the process $\mathrm{Y}(\mathrm{t})$ presents some dependence properties and some non stationarity properties. If $g$ is still time dependent, it just means that the detrended process has a remaining deformation trend. In this study, our aim is only to estimate the central trends $\mathrm{m}(\mathrm{t})$ and $\mathrm{s}^{2}(\mathrm{t})$. 


\subsection{Trend estimation}

\subsubsection{Estimation methods}

Time series associated with climate variables such as temperature are non stationary and non Gaussian. In order to estimate the central trends $m(t)$ and $s^{2}(t)$ as intrinsically as possible, in the first place we will avoid using either moving average with a window length $\mathrm{h}$ or linear regression. The window length $\mathrm{h}$ fixes the time scale taken into account, that is the period over which the average is computed, and linearity is a strong assumption concerning trends.

Parametric modelling such as linear regression is widely used to analyse trends in mean or in variance. However, it can constrain excessively the range of possible fits for exploratory modelling, it looses a large amount of information given for instance by shorter time scale evolutions and might not be adapted to complex issues arising from climate studies, except for some particular cases.

In an other work (Yiou et al., 2008), we have seen that seasonal means and variances are correlated for some areas in Europe in winter and summer. Here, we would like to go further in looking for the time evolutions of the means and variances, and their possible connections, in the most general way as possible, thus in using non parametric methods. In the present work, time scale has to be thought of as linked to the speed of evolution of annual data. The evolution during a fixed year is mainly due to seasonality and reveals only a small component of the large temporal scale evolution. Therefore, the choice of the set of functions able to describe trends is a quite difficult problem. The idea is to fix a degree of smoothness such that the trend does not show too many local extrema and inflexions. It roughly corresponds to a trade-off between capturing the structure in the data and in the same time, smoothing the local extrema. In fact the choice has to be adapted to the analysed data to keep the trend identification as intrinsic as possible. A discussion of this topic can be found in Wu et al. 2007 concerned with the application of specific methods based on physical characteristics, but this is out of the scope of this paper and can not take into account a variation of the variance. Classical non parametric methods such as cubic splines, penalized least squares, LOESS, wavelets etc. have adaptive variants which allow to choose 
intrinsically the scale of evolution without any a priori hypothesis about the data, the "smoothness" being estimated (Bickel 1992).

Each method relies on some "technical" parameters and the adaptive character consists of an optimal (in a statistical sense) estimation of these parameters from the data. Each of these methods allows a visual description of the trend in the resulting plot of the response versus time, making them very flexible. Here we use two popular methods: cubic splines smoothing (Green and Silverman, 1994) and local polynomial estimators (LOESS) (Fan and Gijbel, 1996). Cubic splines smoothing consists in looking for a twice differentiable function which represents optimally the evolution of the mean of the observed data. The smoothing parameter happens to be a penalization term which does not allow too many inflexions.

LOESS consists in looking for the polynomial of degree $d$ that corresponds best to the representation of the regression between the variable and the covariate (here, the covariate is time) on an optimal window length. The optimal window length is defined by the parameter $\lambda$, which corresponds, if smaller than 1 , to the proportion of the total number of data used for the local regression. Thus, the window length $h$ (in years) equals $\lambda$ times the total number of years in the analysed data series. Then, local regression is applied with a tri-cubic weighting proportional to

$$
\left(1-(\text { dist } / h)^{3}\right)^{3}
$$

where dist is the distance between two values ( 1 day in our application) and $h$ the window length. This allows adding more weight to neighbouring points and less to more separated ones.

Thus, cubic splines give a trend function optimised on the whole series length giving the best curvature, whereas LOESS follows more locally the regression between the two variables.

We used both cubic splines and LOESS to model functions of mean and variance of the whole observation set $\left(\mathrm{m}(\mathrm{t})\right.$ and $\left.\mathrm{s}^{2}(\mathrm{t})\right)$, and both methods give very similar results. Therefore, in the following, we will only present the results for the LOESS, which is the most convenient. The proper choice of the smoothing parameter for LOESS is crucial. Adaptive procedures such as cross-validation procedures help in making the right choice, but their efficiency is hindered by highly auto-correlated series such as temperature series. Cross-validation has to 
be modified in order to eliminate the dependence. Here, the dependence between the dates can be considered as zero if the dates are distant by more than 5 days. We thus used a cross validation method on data sampled every 10 days, and an optimal parameter corresponding to a window length of around 11 to 15 years has been found. Another approach is to choose a smoothing parameter using an empirical and efficient way based on learning. We used this alternative as a visual control of our previous choice.

A common problem with smoothing methods is related to boundary problems at the beginning and end of the observation period. The data are all on one side of the fitting point in the boundary case. Thus, using the same algorithm at the boundaries and in the interior leads to higher variability. LOESS can automatically provide boundary bias correction. Fitting local polynomials at values in the boundary region, the bias is small, and can therefore be ignored. The calculations are conducted as follows:

- selection of the days of the studied season over the total period length (this leads to a series of nyear $\bullet 100$ days for summer and nyear $\bullet 0$ days for winter, nyear being the number of years in the total period length)

- computation of $\hat{m}(t)$ from X(t) using LOESS

- computation of $[\mathrm{X}(\mathrm{t})-\hat{m}(t)]^{2}$

- computation of $\hat{s}^{2}(t)$ from $[\mathrm{X}(\mathrm{t})-\hat{m}(t)]^{2}$ using LOESS

where the hat notation corresponds to estimates.

Thus, the time evolution of the variance takes into account the time evolution of the mean. The estimation is not done using the likelihood (unknown), but using least squares. This methodology, and in particular the estimation of $m(t)$ and then that of $\mathrm{s}^{2}(\mathrm{t})$, has a clear theoretical support for large data samples as ours (Ruppert et al., 1995).

In order to illustrate the role of the smoothing parameter, figure $2 \mathrm{a}$ presents the trends $\mathrm{m}(\mathrm{t})$ identified in summer temperatures for the long summer temperature series of Deols between 1901 and 2006 using a linear local regression with a smoothing parameter corresponding to a 15 -year window (15 summers here, i.e. 1500 days) and using a moving average on the same window. The two trends are superimposed over the evolution of the summer means computed from the data series (for each day in a summer, the temperature is set to the mean summer 
temperature). It can be seen that LOESS is able to reproduce better small data variations, where moving averages tend to lead to a higher smoothing (top panel). To capture the same details as obtained with LOESS, the moving average window must be twice as small, that is around 7 years, as shown in the bottom panel. On the other hand, the choice of linear local regression has been compared to a quadratic local regression (figure 2b). It can be seen that the details are enhanced in using quadratic local regression, but it has been judged sufficient for the study to use linear local regression.

\subsubsection{Bootstrap confidence intervals}

It is now necessary to quantify the uncertainties associated with the estimation of the mean and variance evolutions. To do so, the construction of a confidence interval is based on the residual bootstrap resampling, which is simple and chosen because it does not rely on the evaluation of quantities according to some asymptotic property.

There exists a widely developed theory for asymptotic confidence intervals (Hall, 1991, 1992, Faraway and Jhun, 1990, Härdle and Mammen, 1993 and Neumann, 1992, 1995).

We choose to construct a pointwise confidence interval based on bootstrap percentiles. It is well adapted to our estimation method because it does not artificially assume normality and it is simple to implement for our large datasets. Here because of the dependence of the data, we use moving blocks bootstrap (Lahiri, 2003) with a size of 10 days, and we simulate 2000 samples. The results obtained for the evolution of the mean of summer daily maximum temperature for the long series of Deols (1901-2006) are plotted in figure 3.

\subsection{Possible link between the estimated trends $m(t)$ and $s^{2}(t)$}

Using the previously presented non parametric methods, the functions $\mathrm{m}(\mathrm{t})$ and $\mathrm{s}^{2}(\mathrm{t})$ are estimated by $\hat{m}(t)$ and $\hat{s}^{2}(t)$. Suppose that these estimates are two functions with a strong link, measured for instance by a scalar product close to one (which indicates more a linear link). Could this link be produced by some statistical artefacts?

Firstly, for a large dataset, all the procedures used here give consistent estimators, roughly speaking the speed of estimation is of the order of $\mathrm{N}^{-\mathrm{a}}(\mathrm{N}$ being the 
number of values in the dataset), $a>0$ and depending on the chosen degree of smoothness for the trend.

The estimation errors $\mathrm{m}(\mathrm{t})-\hat{m}(t)$ and $\mathrm{s}^{2}(\mathrm{t})-\hat{s}^{2}(t)$ are asymptotically correlated but their correlation is too weak in $\mathrm{N}^{-2 a}$ to be the source of the identified link. In fact, for a large dataset (see the appendix and Ruppert et al., 1995), we can first estimate $\mathrm{m}(\mathrm{t})$ and then $\mathrm{s}^{2}(\mathrm{t})$, as we do, and this is as efficient as a direct estimation of the pair $\left(\mathrm{m}(\mathrm{t}), \mathrm{s}^{2}(\mathrm{t})\right)$.

Now can the link be induced by the density probability functions $f(x, t)$ of the data itself? As a matter of fact, all the information on the data $\mathrm{X}(\mathrm{t})$ is given by its probability density function. However, a link between $m(t)$ and $s^{2}(t)$ does not necessarily imply some defined form of the probability density function.

All the calculations are made using the free R statistical software.

\section{Results for the different observational datasets}

\subsection{ECA\&D temperature series}

The first task has been to choose the smoothing parameter. As we want to study a large number of series, it is either necessary to automate the adaptive choice of the smoothing parameter or to fix it in advance. As previously mentioned, a parameter corresponding to a window length of around 11 to 15 years has been found in most cases. Figure 4 shows the mean evolution for long daily maximum temperature series of Deols (1901-2006) using different window lengths: 10, 15 and 20 years (or summers as we only keep the 100 summer days each year). As expected, the larger the window is, the smoother the curve appears. In the following, the results for a 15 -year window length will be shown in order to simplify the exposition.

The LOESS technique with a 15 -year window length is applied to compute the evolution of mean and variance of daily minimum temperature in winter and daily maximum temperature in summer. The results for the series of Smolensk in winter and La Rochelle in summer are presented figure 5, together with the 90\% confidence intervals. These results suggest a strong link between the evolution of mean and variance, with the variance increasing at the same time as the mean in summer and decreasing as the mean increases in winter. In particular, there is a 
quite perfect correspondence between the local extremes. To examine the dependence between those two series, we can compute correlation coefficients which correspond to the scalar product (divided by the Euclidian distances). Another way to look at the resemblance between two curves is to compare their parallel slopes, thus we can compute the correlation coefficients between their first derivatives too.

We compute correlation coefficients between the two curves or their first derivatives for all the 55 time series. Correlation coefficients are thought as we said previously as a measure of the linear relation between two functions $m(t)$ and $s^{2}(t)$, say of the possibility to get a good approximation of $s^{2}(t)$ by an affine function $a+b m(t)$. This similarity could be evaluated through other measures, such as for example the link between their first derivatives, as stated before. Thus here, the link between the two curves, is measured by the correlation coefficient and has been considered as significant if the correlation coefficient exceeds 0.2 in summer and is lower than -0.2 in winter. According to this criterion, all correlations but one (for the Petsjora series) are significant in winter and all but 8 (Alger, Elatma, Kem, Smolensk, Sortavala and Vilnius series) in summer. The top panel of figure 6 shows the maps of the correlations coefficients between the evolution of mean and variance of daily minimum winter temperatures on the right and the same significant correlation coefficients between their first derivatives on the left. The bottom panel shows the same results in the same way for daily maximum summer temperatures. Correlation coefficients between $m(t)$ and $s^{2}(t)$ or between their first derivatives give very similar results: they are rather strong in winter, except along the coasts and in the most northern regions. In summer, correlations are strongest for locations experiencing more temperate climate than for those with more continental climate. In the following, we will only show the results for the correlation coefficients between the evolutions of the mean and the variance $(\mathrm{m}(\mathrm{t})$ and $\left.\mathrm{s}^{2}(\mathrm{t})\right)$.

\subsection{ENSEMBLES gridded dataset}

In order to extend and verify the previous statement, the same analysis of correlation coefficients between the evolutions of mean and variance for daily minimum temperature in winter and daily maximum temperature in summer has been performed using the ENSEMBLES gridded dataset. As previously 
mentioned, this dataset is on a 0.5 degree regular grid and has been constructed from the best available observation datasets, including those used in the ECA\&D project. Many grid point series show an important number of missing values (all values missing in some cases) thus the analysis has been made only for those series presenting less than $10 \%$ of missing values. The remaining missing values have been replaced by the climatological mean of the corresponding day. Results for correlation coefficients between the evolution of mean and variance of daily minimum winter temperatures and daily maximum summer temperatures are presented in figure 7 . The results are consistent with the previous ones, showing strong negative correlations in winter for the central part of Europe except some of the coastal areas. In summer, the picture is more contrasted: high positive correlations are found for France, the south of Great Britain and some areas in south east of Europe, but weaker, although still positive, correlation elsewhere.

\subsection{The ERA40 reanalysis}

The last test has been done using the results of the ECMWF ERA40 reanalysis project, in order to verify the results on a dataset whose homogeneity is ensured by construction. Results are presented figure 8 . They are very similar to the previous ones and confirm the relationships: the variance decreases when the mean increases in winter for most of the central part of Europe and the variance increases when the mean increases in summer in France and Great Britain and in some parts of central Europe near the Black Sea.

\subsection{Results summary}

\subsubsection{Cold season}

All datasets lead to similar conclusions with strong negative links between the evolution of mean and variance of minimum daily temperature in winter over a large part of central and northern Europe. However some regions around the Mediterranean and the Black Sea show positive correlation coefficients, in the ENSEMBLES gridded dataset (top of figure 7) as well as in the ERA 40 reanalysis (top of figure 8). Figure 9 shows evolutions of mean and variance for a grid point in the ENSEMBLES gridded dataset near Smolensk, where the correlation coefficient is strongly negative, and a grid point in Spain, where the 
correlation coefficient is positive, in winter. The plot for the grid point near Smolensk strongly resembles the one for the ECA\&D Smolensk series (figure 5), which is not surprising, as the same series have been used to produce the ENSEMBLES gridded dataset. For the point in Spain with positive correlation coefficient, it can be noted that the variance evolution is rather weak and the mean is rather warm, which could explain our results. The same behaviour is found for all rather strongly positive correlation coefficients in winter.

\subsubsection{Hot season}

In the summer season the picture is more contrasted, with rather high correlation coefficients in France and Great Britain and in some parts around the Black Sea. Correlation coefficients remain positive over a large part of Northern and central Europe, although lower than 0.5 . Here, the points showing strong negative correlation coefficients correspond to two different types of behaviour: most of them correspond to very hot summers, and others seem to correspond to points where the effect of altitude is strong, with rather mild summers (points in Switzerland and northern Italy). Figure 10 shows the evolution of mean and variance of maximum daily temperature in summer for two points of the ENSEMBLES gridded dataset: a point near La Rochelle, with a strong positive correlation coefficient, and a point in Spain with a strong negative coefficient. The evolution of the mean and variance for the grid point near La Rochelle is very similar to those of the series of La Rochelle in figure 5 for the same reason as explained in the previous section. For the point in Spain, the temperature is warm and seems to be less variable when it is warmer.

The method used here to derive trends describes the evolution over a continuous set of time scales and it is difficult to infer which scale is the most responsible for the observed link between mean and variance (day to day, intra seasonal scale or inter seasonal scale). This could be further investigated using for example wavelet analysis. However, from an analogous study made on seasonal mean and variance (Yiou et al., 2008), it can be seen that the intra seasonal variability plays an important role. This means that in some regions, a very cold winter or a very warm summer is more variable. This could be due to non permanent hot or cold episodes, interrupted by milder ones, and this could be the explanation for a 
strong link in France and Great Britain during the summer period for example. This hypothesis should be further investigated by studying episodes for some particular series. For example in Spain, where summers are hot, the variance increases when the mean is lower, and one could wonder if there exists a summer mean threshold above which the behaviour reverses.

\section{Results for 6 European climate models}

The study on different observation datasets shows some robust relationships between the evolution of mean and variance of daily minimum temperature in winter and daily maximum temperature in summer. The aim of this section is then to investigate if climate models reproduce a similar link. To do so, we used results of the simulation for the period 1961-2000 conducted with five different climate models and for the period 1950-1999 for one other climate model, elaborated by European research teams. The models are:

- $\quad$ bccr-bcm2-0 of the university of Bergen in Norway

- $\quad$ cnrm-cm3 of the French meteorological office research centre (Centre de Recherches Météorologiques de Météo-France)

- $\quad$ ipsl-cm4 of the Institut Pierre-Simon Laplace in Paris, France

- mpi-echam5 of the Max Planck Institute for meteorology in Hamburg, Germany

- ingv-echam4 of the National Institute of Geophysics and Volcanology in Bologna, Italy

- ukmo-hadgem1 of the United Kingdom Meteorological Office Hadley Centre, over the period 1950-1999

Simulations of these models obtained in the framework of the fourth IPCC assessment are available from the PCMDI web portal.

We applied the same methods as described above and obtained results summarised in figure 11 for winter and 12 for summer. A comparison of these figures with those obtained from the observational datasets (figures 7 and 8) shows that the models generally fail to reproduce the observed link between the evolutions of the mean and the variance of temperature. Except for cnrm-cm3, the models seem to perform better in winter than in summer, especially the ingvecham 4 model and the bccr-cm2-0 model. Curiously, these models share their atmospheric component (although in a different version) with other ones (mpi- 
echam5 for ingv-echam 4 and cnrm-cm3 for bccr-bcm2-0) whose results are less good. In summer, all models fail to capture the observed link correctly. This puts in doubt the representation of temperature variability by current climate models.

\section{Conclusion and perspectives}

In this paper we tried to use as far as possible the properties of non parametric methods in statistics to obtain general qualitative properties on the time evolution of temperatures in Europe over periods of at least 50 years.

The first conclusion is that the mean and variance for hot and cold seasons have a very similar evolution: the variance increases as the mean increases in absolute value, i.e. it increases when daily maximum summer temperatures increase and when daily minimum winter temperatures decrease. This link seems to be more general in winter for a large part of central Europe, even though it is weaker in coastal areas, whereas in summer it is limited to areas where summers can experience heat waves without being in average too mild or too warm. This result is found whatever the observational dataset used, the ECA\&D data series, the ENSEMBLES daily gridded dataset or the ECMWF ERA40 reanalysis, each available on different period lengths over the $20^{\text {th }}$ and the beginning of the $21^{\text {st }}$ century. Accordingly, the result seems to be robust. This could be explained by the fact that in these areas, cold winters or warm summers are associated with some very cold or very warm episodes, interrupted by more "normal" conditions, in relationship with the large scale atmospheric circulation. This hypothesis will be investigated by advanced studies on episodes during summer/winter seasons. On the other hand, climate models generally fail to correctly reproduce this link, although their behaviours seem to be better in winter than in summer. The ingvecham4 model, and to a lesser extend the bccr-bcm2-0 model show rather good results in winter, whereas all the studied models fail to correctly reproduce the observed link in summer. Thus, the models cannot be trusted for the reproduction of temperature variability in their current versions.

A further step will then be to carefully study the link between evolutions of mean and variance and the evolution of extremes, using statistical extreme value theory and similar techniques to derive non parametric evolutions. A first analysis of this link is presented in Nogaj et al. 2007, but a more systematic study is needed to obtain more robust results. 


\section{Appendix}

We have defined $Y(t)=[X(t)-m(t)] / s(t)$. Deformation trends are trends able to partially describe the remaining non stationarity in the distribution of $\mathrm{Y}(\mathrm{t})$. A first result concerns the non stationarity of the extremes of $\mathrm{Y}(\mathrm{t})$ and is exposed in Nogaj et al., 2007. Other remaining trends can be found using the probability density function of the residuals $\mathrm{Y}(\mathrm{t})$.

This is illustrated in figure 13 with two estimates of this probability density function for the station of Deols in summer. The first one is constructed from the data during the first 15 years of observation and the second one during the last 15 years. We also can read in table 2 the evolution of the skewness (here simply the third moment because $\mathrm{Y}$ is centred, with variance 1 and kurtosis, here the fourth moment, minus 3). These quantities do not seem to evolve with time, the relative variation being always less than 1/10.

We mentioned in section 3.3 that our method can be applied for non stationary Y if the fourth moment is bounded. It can be seen that it is the case here, it is bounded by 4 and moreover the estimation of the parameters of extreme distribution shows that this distribution is bounded for Y (this can also be seen on the previous estimation of the probability density function in figure 13). The correlation between the $\mathrm{Y}(\mathrm{t})$ is zero for time distances larger than 4, so LOESS can safely be applied.

Acknowledgments We acknowledge the climate dataset from the EU-FP6 project ENSEMBLES (http://www.ensembles-eu.org) and the data providers in the ECA\&D project (http://eca.knmi.nl)

We acknowledge the modeling groups for making their simulations available for analysis, the Program for Climate Model Diagnosis and Intercomparison (PCMDI) for collecting and archiving the CMIP3 model output, and the WCRP's Working Group on Coupled Modelling (WGCM) for organizing the model data analysis activity. The WCRP CMIP3 multi-model dataset is supported by the Office of Science, U.S. Department of Energy.

References 
Bickel, P. J. and Ritov, Y.: Testing for goodness of fit: A new approach. In Nonparametric Statistics and Related Topics A. K. Md. E. Saleh, ed., 51-57, 1992.

Fan, J. and Gijbels, I. : Local polynomial modelling and its applications, Chapman \& Hall, 1996.

Faraway, J.: Bootstrap selection of bandwidth and confidence bands for nonparametric regression,

J. Statist. Comput. Simulation 37, 37-44, 1990.

Ferro, C.A., Hannachi, A. and Stephenson, D.: Simple non-parametric techniques for exploring changing probability distributions of weather, J. Climate, 18(21), 4344-4354, 2005.

Green, P. and Sliverman, B. : Nonparametric regression and generalized linear models , Chapman \& Hall, 1994.

Hall, P.: Edgeworth expansions for nonparametric density estimators, with applications. Statistics 22, 215-232, 1991.

Hall, P.: On bootstrap confidence intervals in nonparametric regression. Ann. Statist. 20, 695-711, 1992.

Härdle, W. and Mammen, E.: Comparing nonparametric versus parametric regression fits. Ann. Statist. 21,1926-1947, 1993.

Hastie , T. and Tibshirani, R.: Generalized Additive Models, Chapman \& Hall, 1990.

Haylock, M.R., N. Hofstra, A.M.G. Klein Tank, E.J. Klok, P.D. Jones, M. New. 2007: A European daily high-resolution gridded dataset of surface temperature and precipitation JGR(submitted)

Katz, R. and Brown, B.: Extreme events in a changing climate: variability is more important than averages, Clim. Change, 21, 289-302, 1992

Klein Tank, A.M.G. and Coauthors, 2002. Daily dataset of 20th-century surface air temperature and precipitation series for the European Climate Assessment. Int. J. of Climatol., 22, 14411453.Data and metadata available at http://eca.knmi.nl Lahiri, S. N.: Resampling methods for dependent data, Springer, 2003.

Neumann, M. H.: Pointwise confidence intervals in nonparametric regression with heteroscedastic Error structure. Preprint No. 34, Institut für Angewandte Analysis und Stochastik, Berlin, 1992.

Neumann, M. H.: Automatic bandwidth choice and confidence intervals in nonparametric Regression, Ann. Statist. 23, 1937-1959, 1995.

Nogaj, M., Parey, S. and Dacunha Castelle, D.: Non stationary extreme models and a climatic application, Nonlin. Processes Geophys., 14, 305-316, 2007

Ruppert, D., Wand, M. P., Holst, U. and Hossjer, O. : Local Polynomial Variance Function Estimation, Technometrics 39, 262-273, 1997.

Schär, C., P.L. Vidale, D. Lüthi, C. Frei, C. Häberli, M.A. Liniger and C. Appenzeller, 2004: The role of increasing temperature variability for European summer heat waves. Nature, 427, 332-336 Simonoff, J.S.: Smoothing methods in statistics, Springer Series in Statistics, 1998.

Yiou P., Dacunha-Castelle D., Parey S., Hoang T.T.H : modeling temperature mean and variability in Europe, submitted to Geophysical Research Letters, 2008

Wu, Z., Huang, N.E., Long, S.R., Peng, C.K. :On the trend ,detrending and variability of non linear and non stationary time series, proc.Nat.Acad.Sci.USA sept 18,104(38) 148896164894, 2007 


\section{List of figures}

Figure 1 : locations of the selected ECA\&D temperature series

Figure 2a : mean summer daily maximum temperature in Deols over the 1901-2006 period (black line) and the corresponding trends computed with LOESS with a window length of 15 years (red line) compared to the same trend computed using a 15-year moving average window (green line) (top panel) and to the same trend computed using a 7-year moving average window (green line) (bottom panel).

Figure 2b : mean summer daily maximum temperature in Deols over the 1901-2006 period (black line) and the corresponding trends computed with LOESS with a window length of 15 years with linear local regression (red line) and quadratic local regression (green line)

Figure 3: Mean summer daily maximum temperature in Deols over the 1901-2006 period (black line) and the corresponding trends computed with LOESS with a window length of 15 years and its $90 \%$ confidence intervals (red lines)

Figure 4 : time evolution of daily maximum temperature mean in summer for the long 1901-2006 Deols series using 3 different window lengths for the smoothing parameter: 10, 15 and 20 years (or summers).

Figure 5 : time evolution of mean $(\mathrm{m}(\mathrm{t}))$ and variance $\left(\mathrm{s}^{2}(\mathrm{t})\right)$ of minimum daily temperature in winter in Smolensk (top) and of daily maximum temperature in summer in La Rochelle (bottom) as computed using the LOESS technique with a smoothing parameter corresponding to a 15 -year window and their $90 \%$ confidence intervals (dashed lines).

Figure 6 : correlation coefficients between the evolution of the mean and the variance (left) and between the first derivatives of mean and variance evolutions (right) of daily minimum temperature in winter (top) and daily maximum temperature in summer (bottom) for the 55 ECA\&D series.

Figure 7 : correlation coefficients between the evolution of mean and variance of daily minimum temperature in winter (top) and daily maximum temperature in summer (bottom) for the ENSEMBLES gridded dataset

Figure 8 : correlation coefficients between the evolution of mean and variance of daily minimum temperature in winter (top) and daily maximum temperature in summer (bottom) for the ERA40 reanalysis dataset

Figure 9 : time evolution of mean and variance of the daily minimum temperature in winter for a grid point of the ENSEMBLES gridded dataset near Smolensk (top) and in Spain (bottom)

Figure 10 : time evolution of mean and variance of daily maximum temperature in summer for a grid point of the ENSEMBLES gridded dataset near La Rochelle (top) and in Spain (bottom)

Figure 11 : correlation coefficients between the evolution of mean and variance of daily minimum temperature in winter for each of the 6 models 
Figure 12: correlation coefficients between the evolution of mean and variance of the daily maximum temperature in summer for each of the 6 models

Figure 13: left panel: probability density functions for $\mathrm{Y}(\mathrm{t})$ estimated from the first 15 (black line) and the last 15 summers (dashed line) of the long daily maximum temperature series of Deols, 1901-2006 and the normal probability density function with mean 0 and variance $1 N(0,1)($ red line); right panel: associated quantile-quantile plot 


\section{List of tables}

Table 1 : location and period length of the ECA\&D selected daily temperature series. The series with different period lengths for maximum temperature (Tx) and minimum temperature (Tn) are written in italics.

Table 2 : Moments of the probability density function of $\mathrm{Y}(\mathrm{t})$ estimated from the first 15 summers and the last 15 summers for the long daily maximum temperature series of Deols, 1901-2006 
Tables

Table 1

\begin{tabular}{|c|c|c|c|}
\hline Location & Country & Period for $\mathrm{Tx}$ & Period for $\mathrm{Tn}$ \\
\hline Alger & Algeria & 1946-1998 & 1946-1998 \\
\hline Armavir & Russia & $1946-2003$ & 1946-2003 \\
\hline Birr & Ireland & 1954-2006 & 1954-2006 \\
\hline Bourges & France & $1946-2001$ & $1945-2000$ \\
\hline Bremen & Germany & $1946-2001$ & $1946-2001$ \\
\hline Calarasi & Romania & 1946-2006 & 1946-2006 \\
\hline Cognac & France & $1946-2006$ & $1947-2006$ \\
\hline Deols & France & $1901-2006$ & 1921-2006 \\
\hline Dresden & Germany & 1917-2006 & 1917-2006 \\
\hline Elatma & Russia & $1946-2003$ & 1946-2003 \\
\hline Elista & Russia & 1946-1999 & 1946-1999 \\
\hline Erfurt & Germany & 1951-2006 & 1951-2006 \\
\hline Halle & Germany & 1946-2006 & 1946-2006 \\
\hline Helgoland & Germany & 1953-2006 & $1953-2006$ \\
\hline Hopen & Norway & 1949-2006 & $1946-2006$ \\
\hline Hoseda & Russia & $1946-2003$ & $1946-2003$ \\
\hline Hurbanovo & Czech republic & $1948-2006$ & $1948-2006$ \\
\hline Ile de Groix & France & 1949-2006 & 1949-2006 \\
\hline Kaliningrad & Russia & 1947-2006 & 1947-2006 \\
\hline Karasjok & Norway & 1951-2006 & 1946-2006 \\
\hline Kaunas & Lithuania & 1946-2006 & 1946-2006 \\
\hline Kem & Russia & $1946-2005$ & 1946-2005 \\
\hline Kempten & Germany & $1952-2006$ & $1952-2006$ \\
\hline Kleine Brogel & Belgium & 1954-2006 & 1954-2006 \\
\hline Kojnas & Russia & $1946-2003$ & 1946-2003 \\
\hline La Rochelle & France & 1946-2006 & $1955-2006$ \\
\hline Leipzig & Germany & $1946-2006$ & $1946-2006$ \\
\hline List & Germany & $1948-2006$ & 1948-2006 \\
\hline Lugansk & Ukraine & 1946-1996 & 1946-1996 \\
\hline Magdeburg & Germany & $1947-2006$ & $1947-2006$ \\
\hline
\end{tabular}




\begin{tabular}{|l|l|l|l|}
\hline Moermansk & Russia & $1946-2003$ & $1946-2003$ \\
\hline Narjan Mar & Russia & $1946-2006$ & $1946-2006$ \\
\hline Onega & Russia & $1946-2006$ & $1946-2006$ \\
\hline Orenburg & Russia & $1946-2003$ & $1946-2003$ \\
\hline Orleans & France & $1946-2006$ & $1946-2006$ \\
\hline Osijek & Hungary & $1946-2006$ & $1946-2006$ \\
\hline Petrozawodsk & Russia & $1946-2003$ & $1946-2003$ \\
\hline Petsjora & Russia & $1946-2003$ & $1946-2003$ \\
\hline Potsdam & Germany & $1946-2001$ & $1946-2001$ \\
\hline Siauliai & Lithuania & $1946-2006$ & $1946-2006$ \\
\hline Smolensk & Russia & $1946-2003$ & $1946-2003$ \\
\hline Sortavala & Russia & $1946-2006$ & $1946-2006$ \\
\hline Syktyvar & Russia & $1946-2003$ & $1946-2003$ \\
\hline Troitzko & Russia & $1946-2003$ & $1946-2003$ \\
\hline Uman & Ukraine & $1946-2006$ & $1946-2006$ \\
\hline Uzhgorod & Ukraine & $1946-2006$ & $1946-2006$ \\
\hline Valley & Enited-Kingdom & $1946-2001$ & $1946-2001$ \\
\hline Vardoe & Norway & $1951-2006$ & $1951-2006$ \\
\hline Verona & Estaly & $1951-2006$ & $1951-2006$ \\
\hline Vichy & $1946-2006$ & $1956-2006$ \\
\hline Vilnius & $1946-2006$ & $1946-2006$ \\
\hline Vilsandi & $1949-2006$ & $1946-2006$ \\
\hline Voru & $1946-2004$ & $1946-2004$ \\
\hline Vytegra & $1946-2006$ & $1946-2006$ \\
\hline Wologda & $1946-2006$ & $1946-2006$ \\
\hline
\end{tabular}

Table 2

\begin{tabular}{|l|l|l|}
\hline & First 15 summers & Last 15 summers \\
\hline Mean & -0.0066 & -0.016 \\
\hline Median & -0.13 & -0.08 \\
\hline Variance & 0.9932 & 0.9987 \\
\hline Skewness & 0.3940 & 0.2814 \\
\hline Kurtosis & -0.2587 & -0.2745 \\
\hline
\end{tabular}


Figures

Figure 1

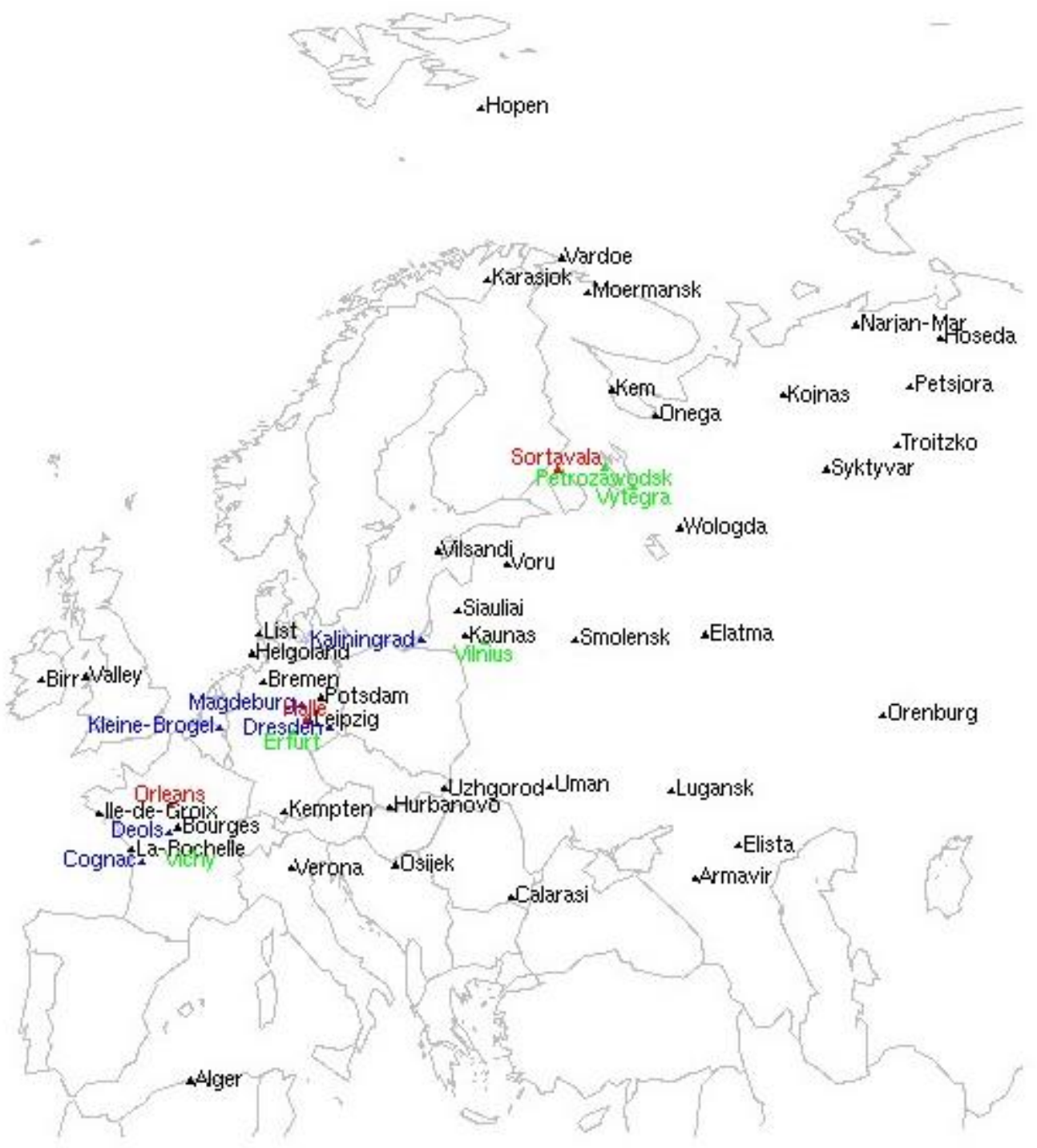


Figure 2a

Deols 1901-2006 summer, LOESS \& MA window: 15 summers

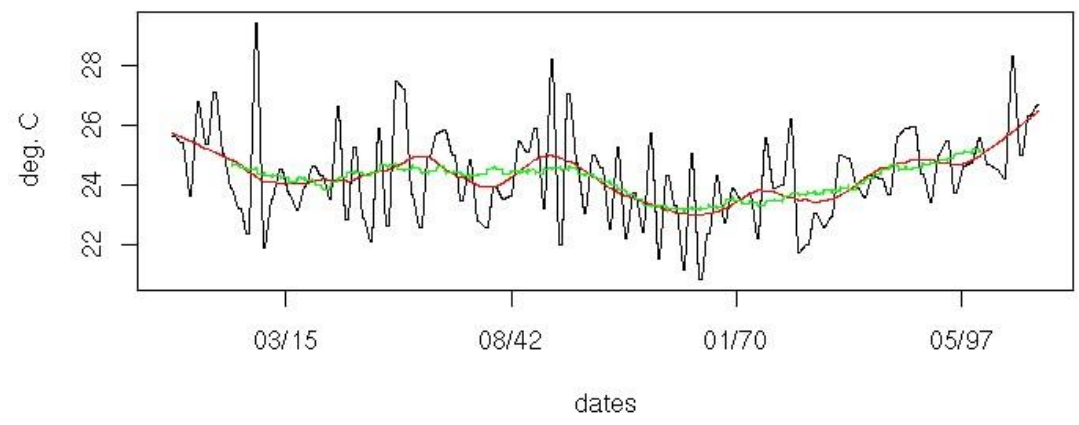

Deols 1901-2006 summer, LOESS window: 15 MA window: 7 summers

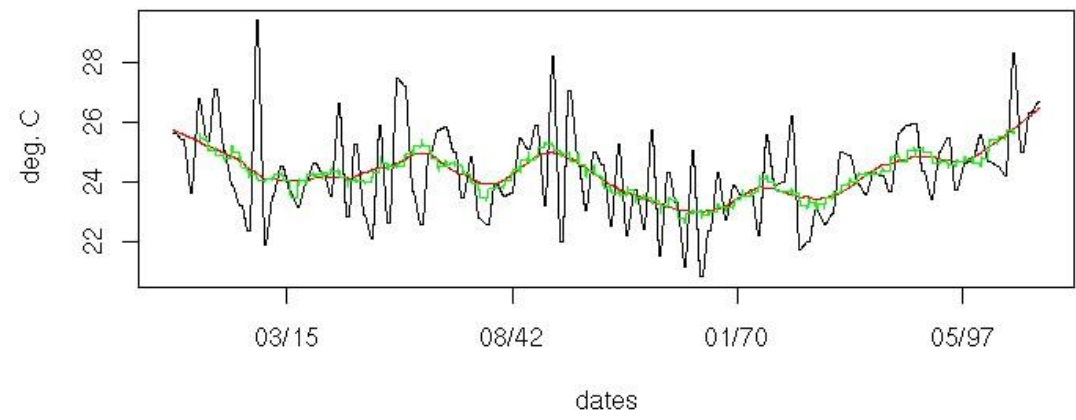

Figure $2 b$

Deols 1901-2006 summer, LOESS d1 \& d2 window: 15 summers

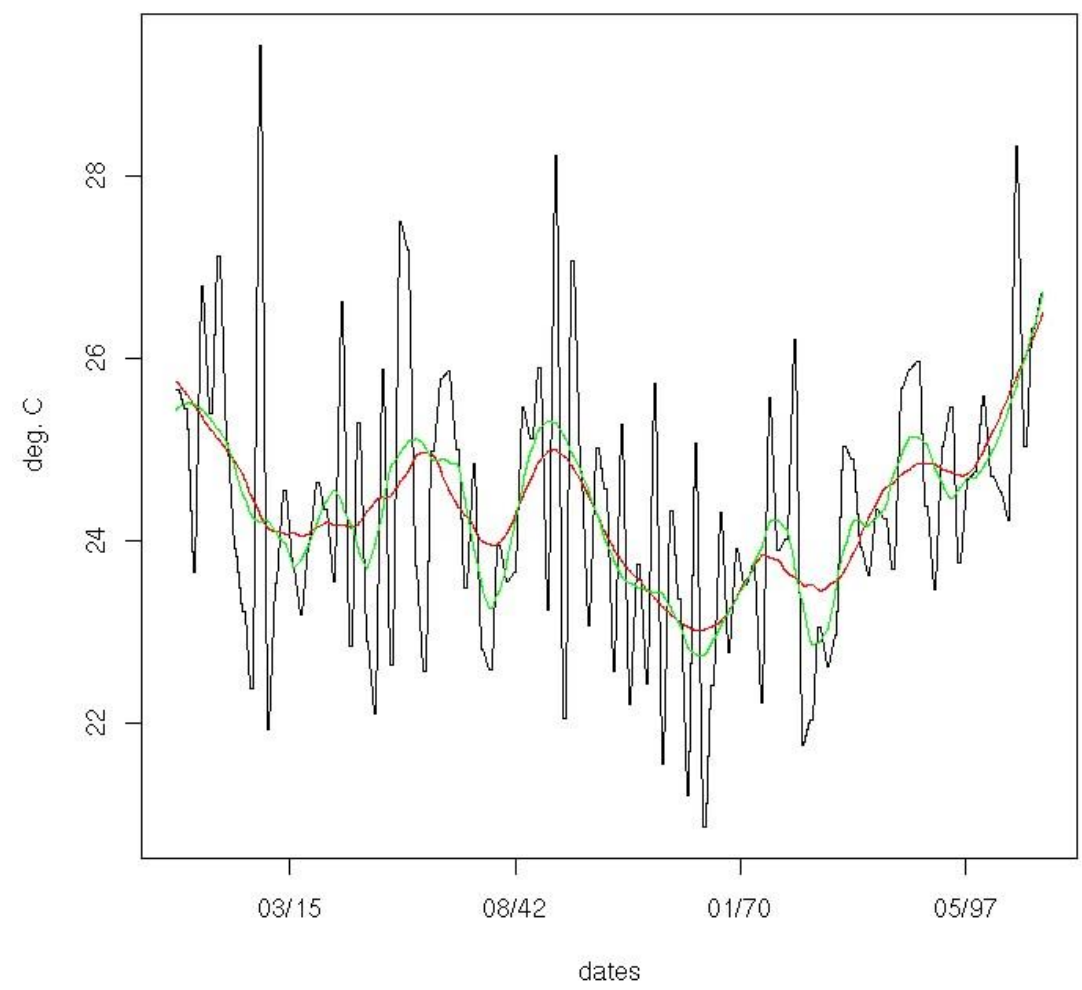


Figure 3

\section{Bootstrap percentile confidence interval_Deols summer}

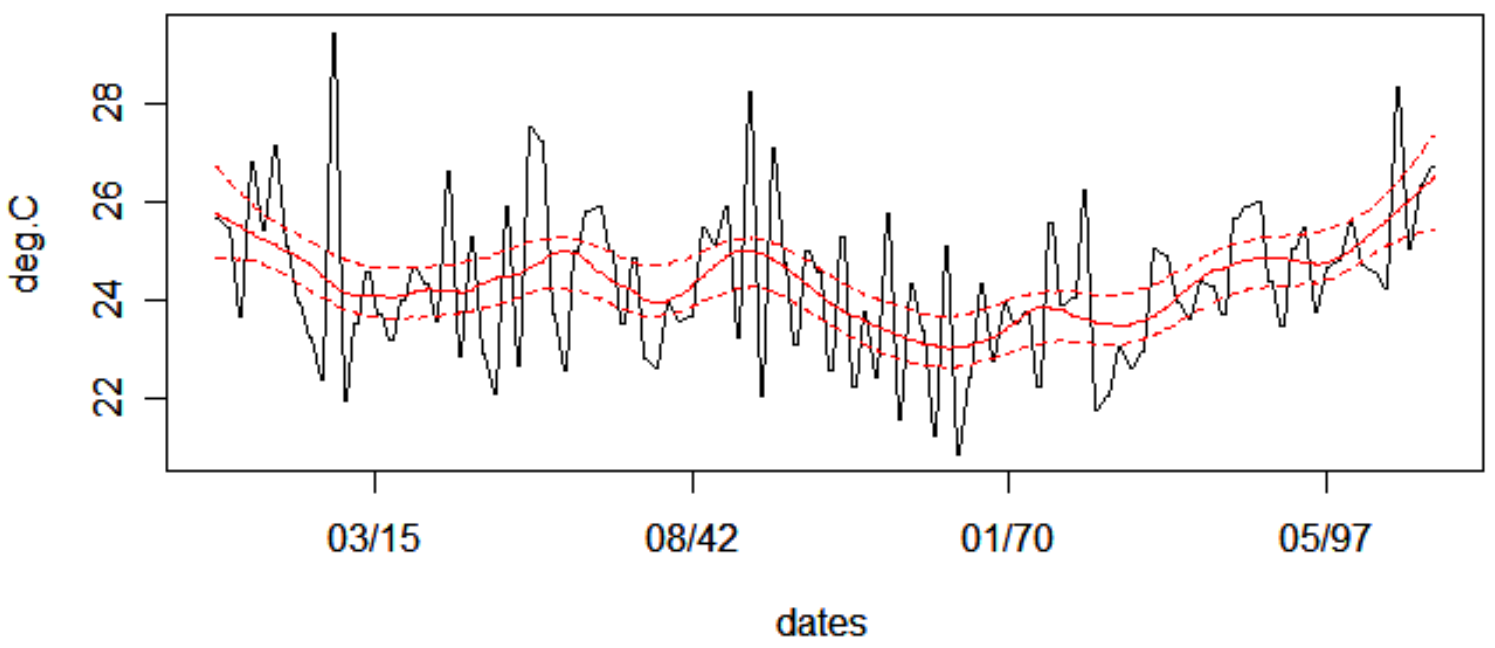

Figure 4

Deols 1901-2006 summer, window: 10 summers

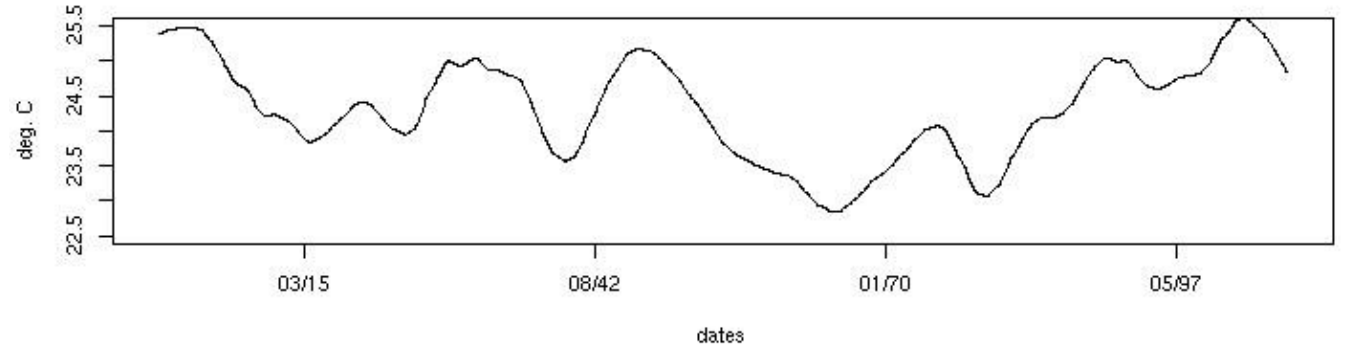

Deols 1901-2006 summer, window: 15 summers

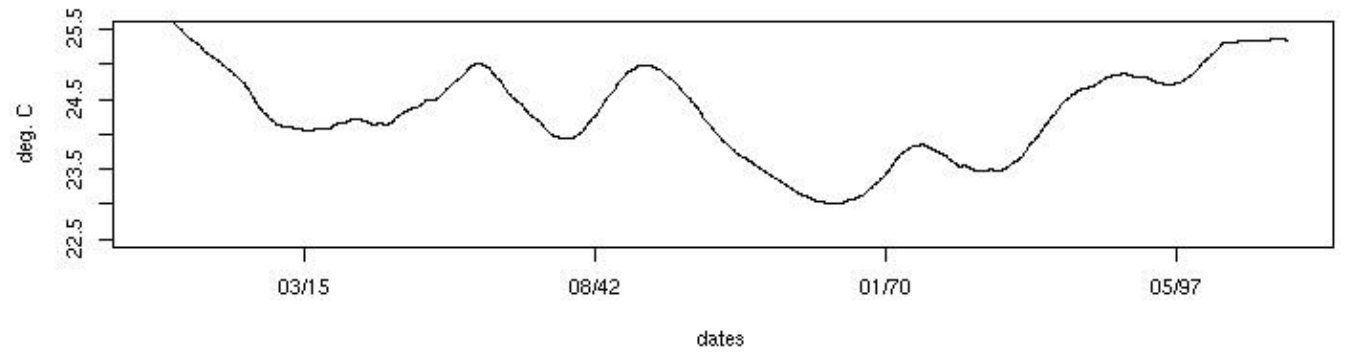

Deols 1901-2006 summer, window: 20 summers

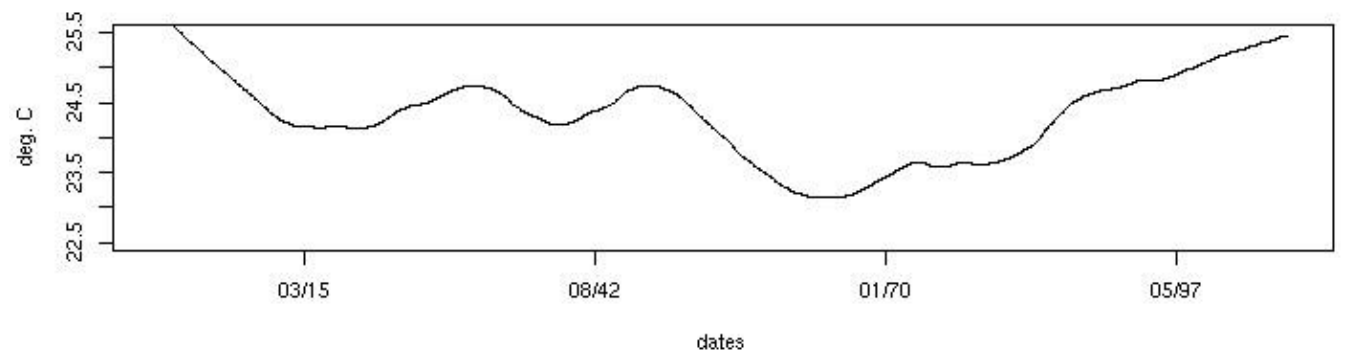


Figure 5
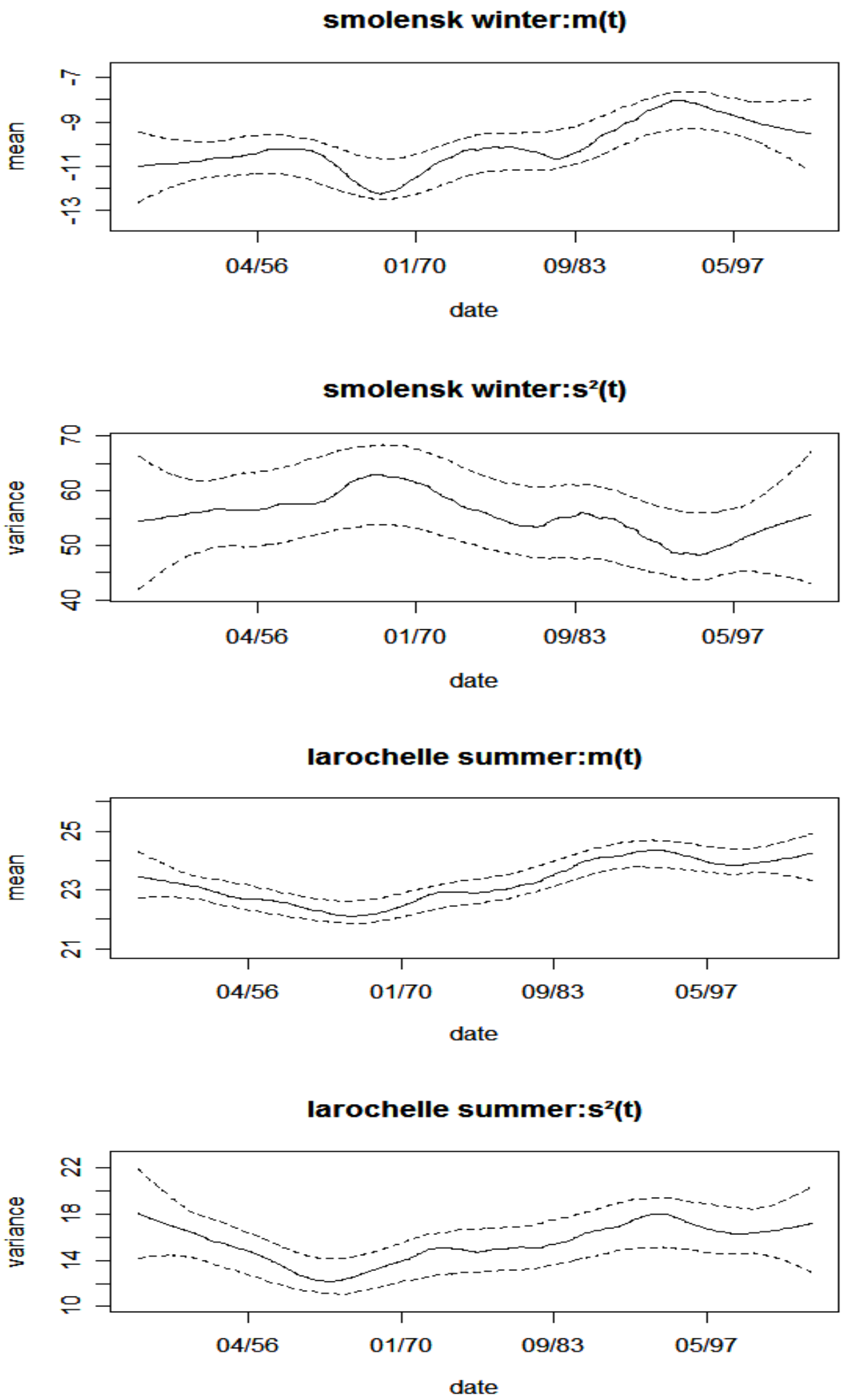
Figure 6

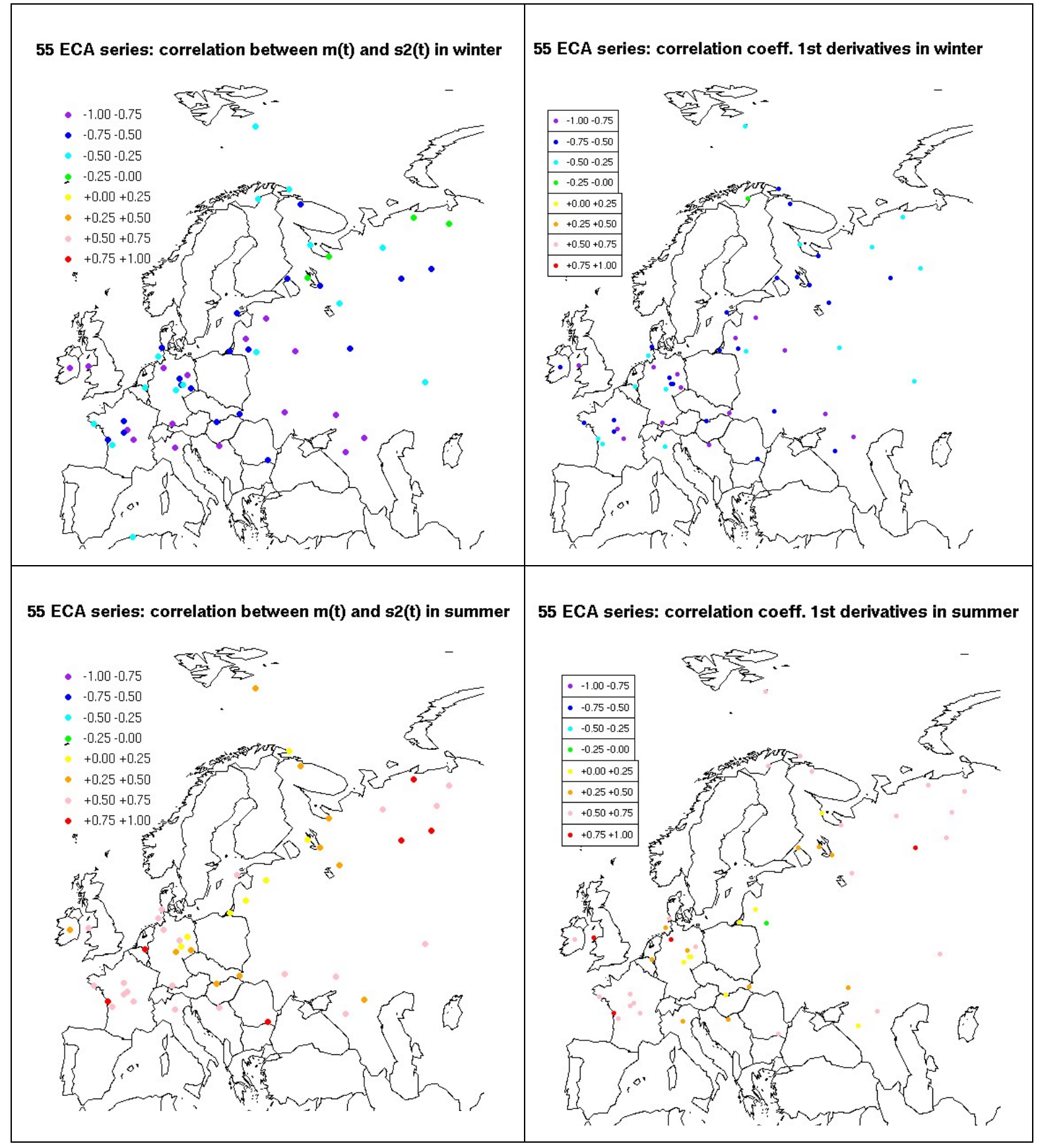


Figure 7

ENSEMBLES gridded dataset: correlations in winter

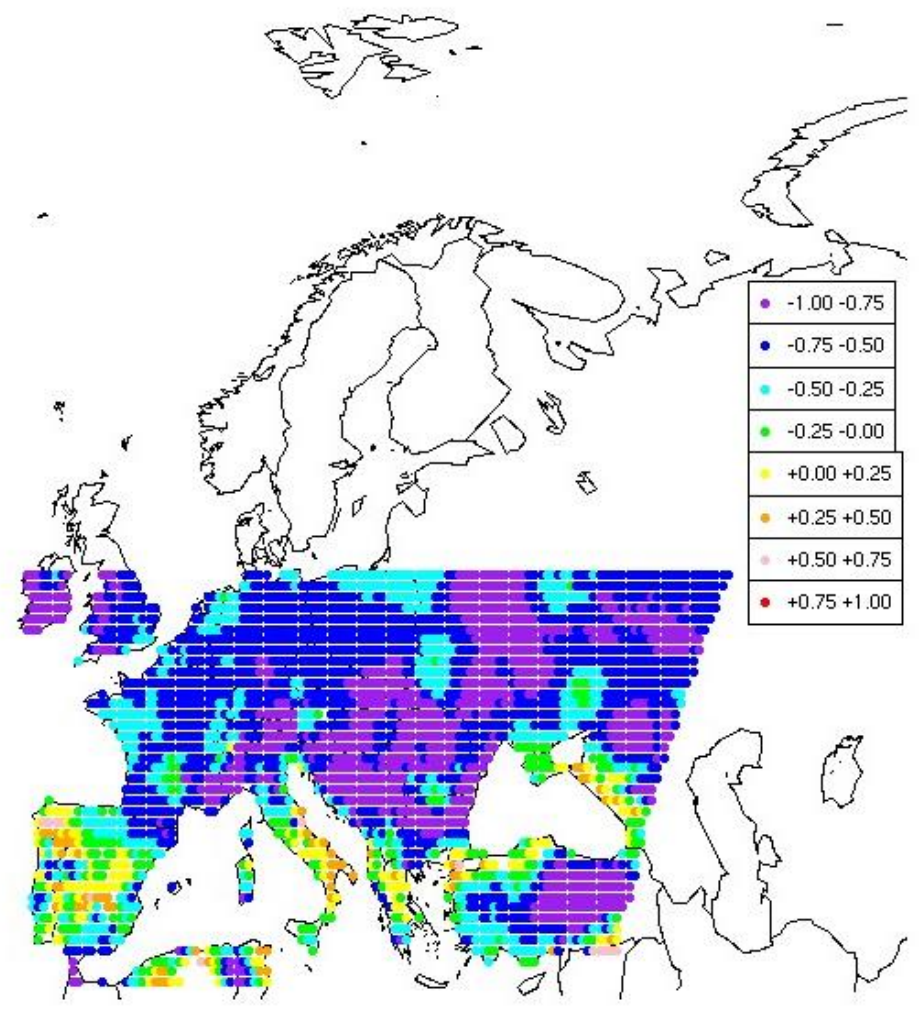

ENSEMBLES gridded dataset: correlations in summer

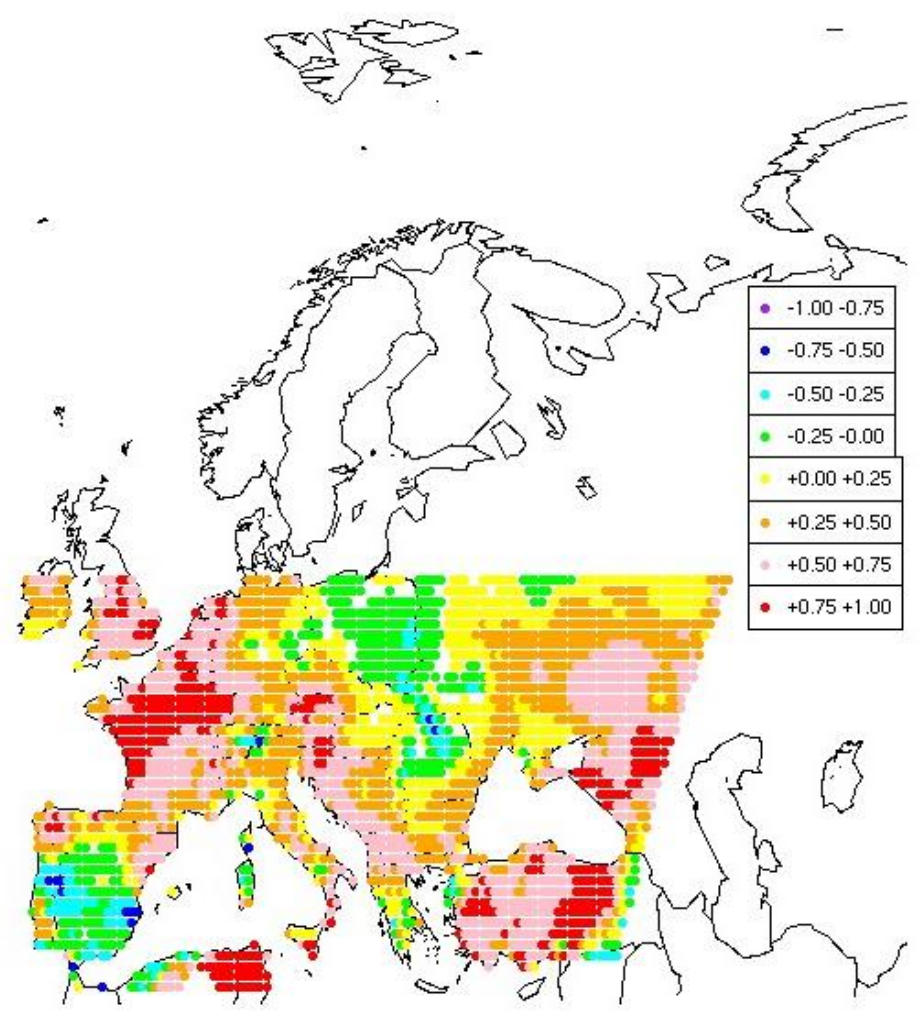


Figure 8

ERA40: correlations in winter

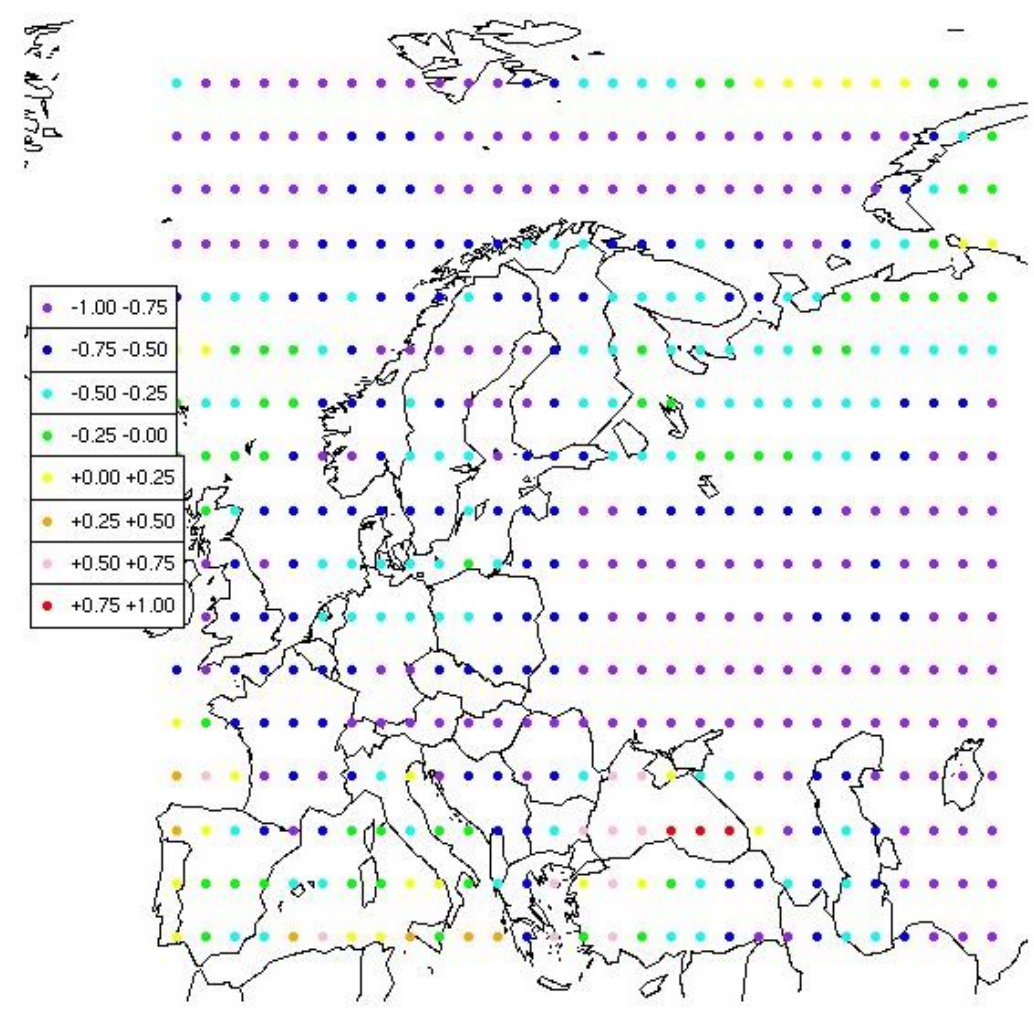

ERA40: correlations in summer

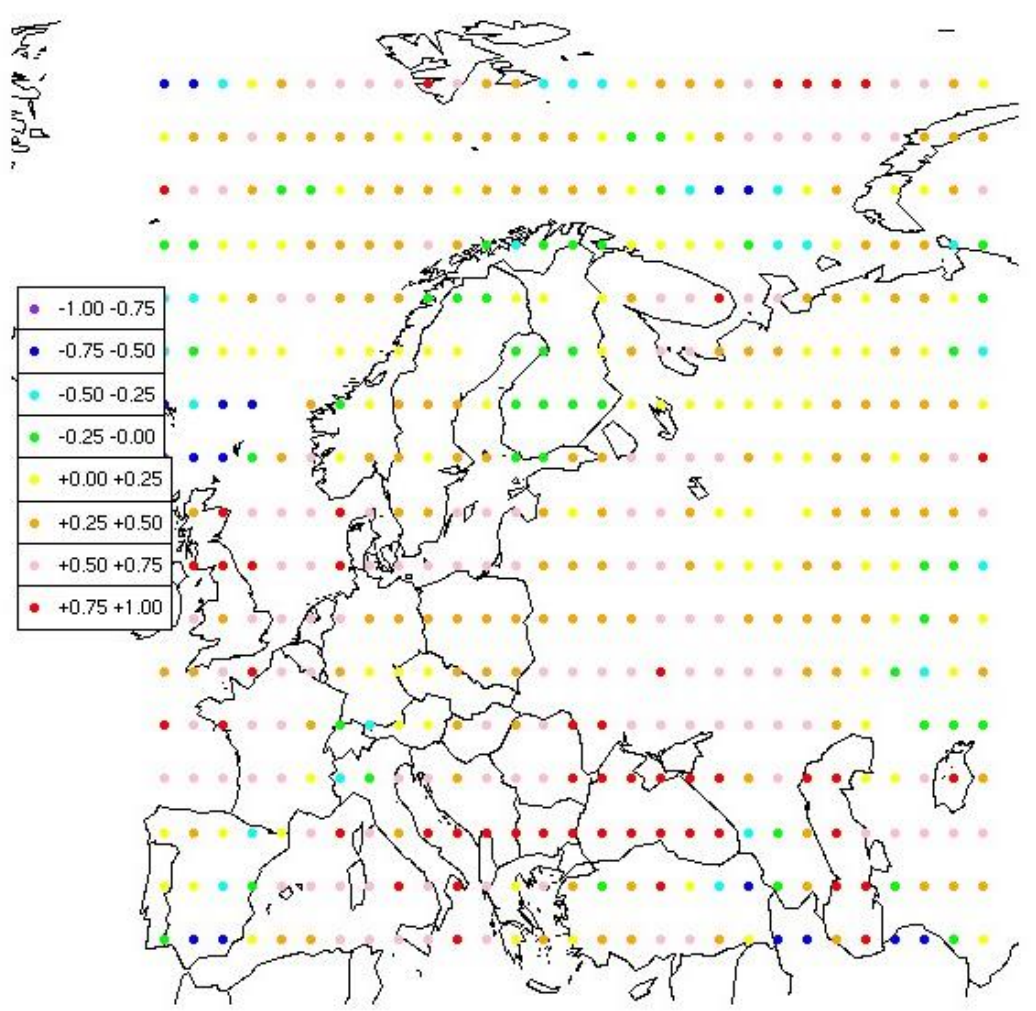


Figure 9
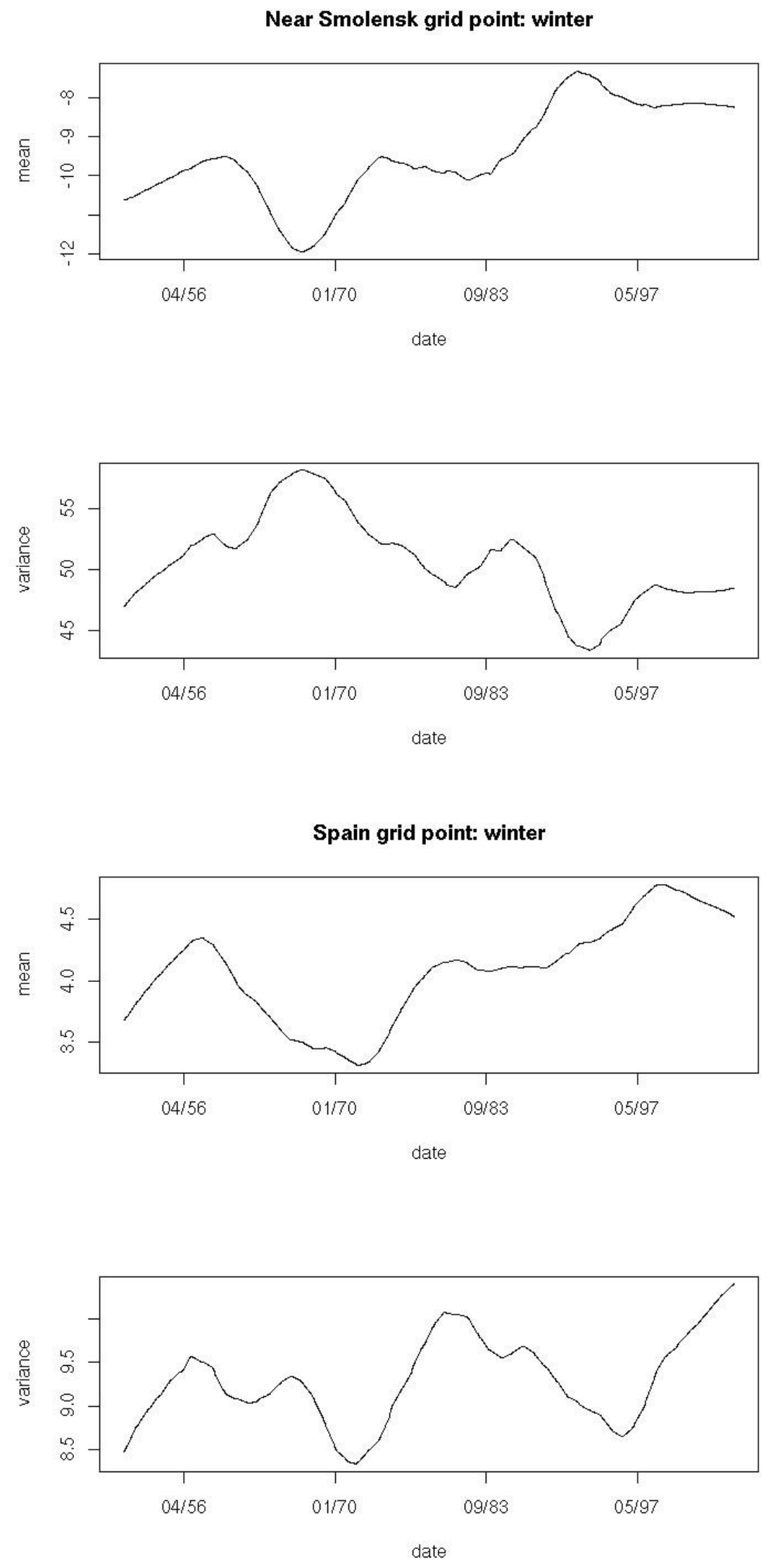
Figure 10
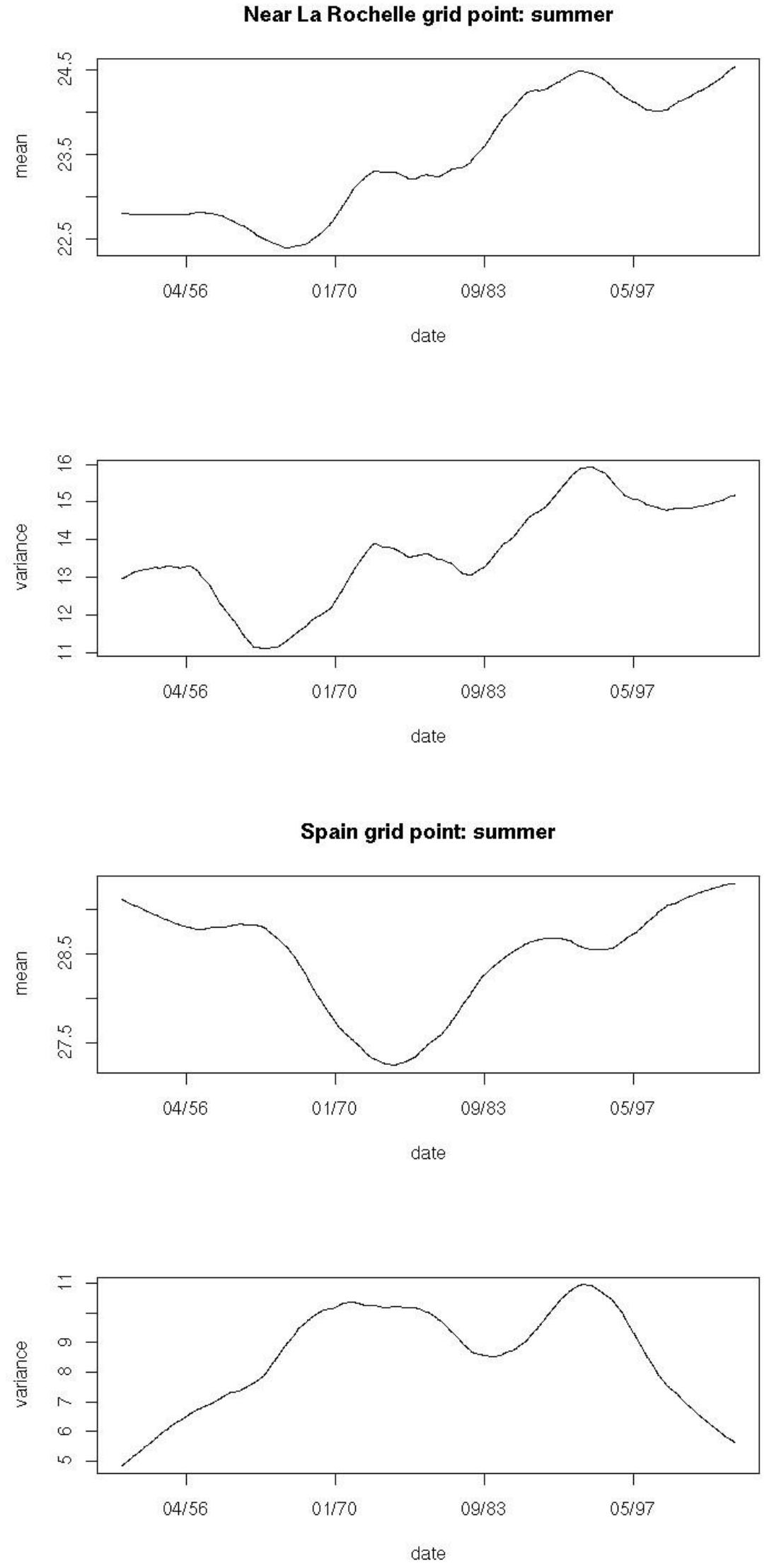
Figure 11

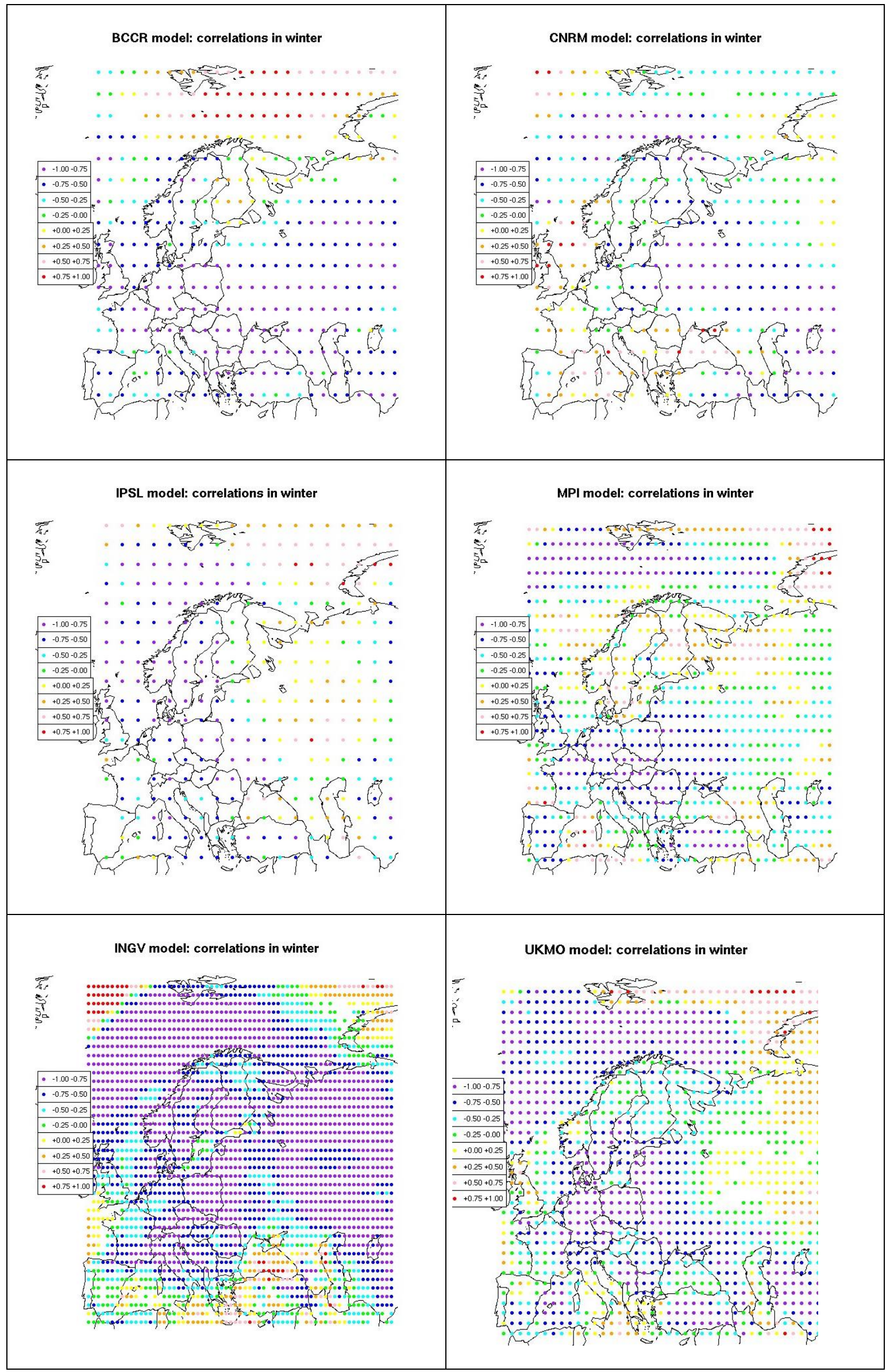


Figure 12

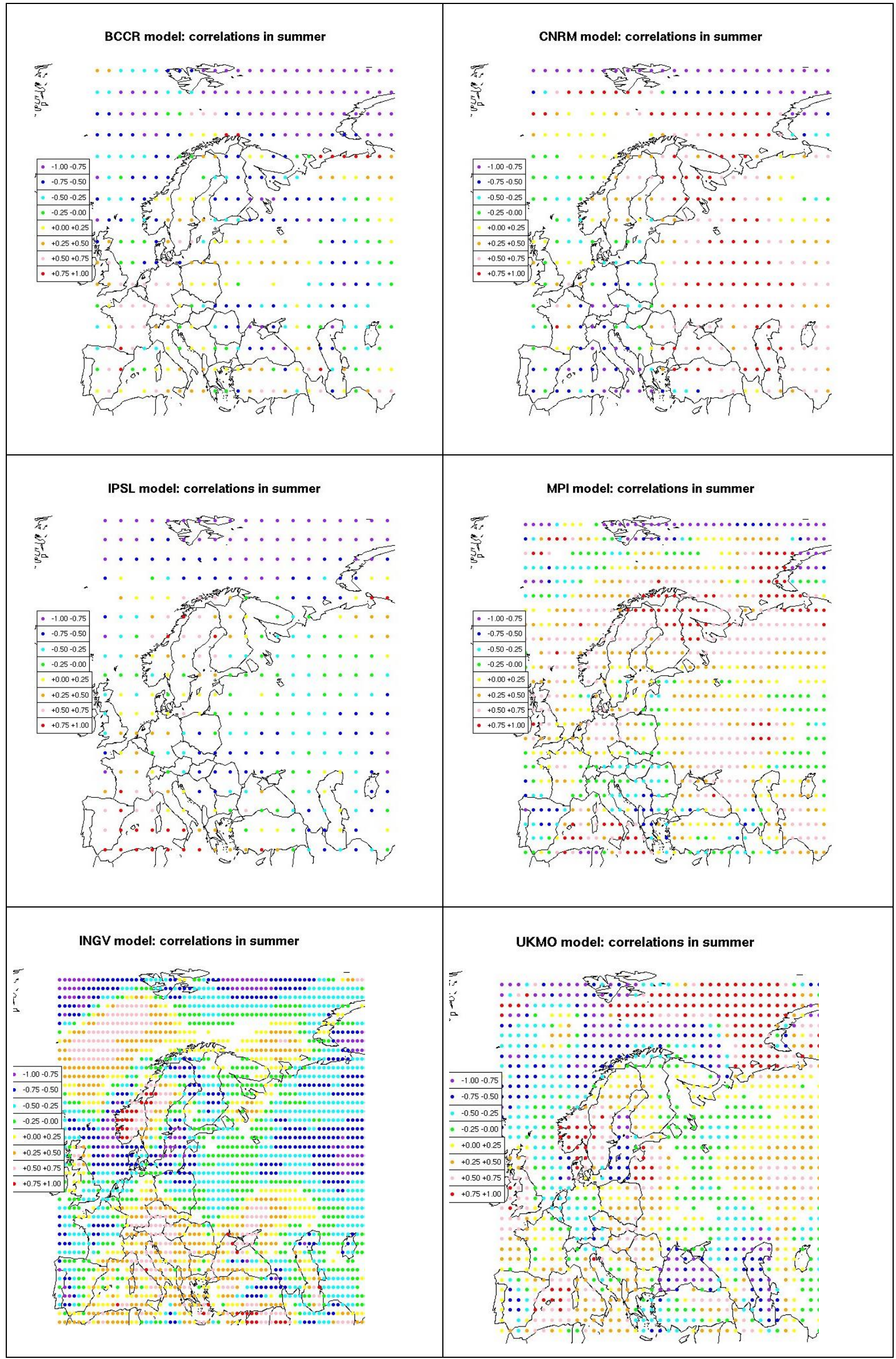


Figure 13
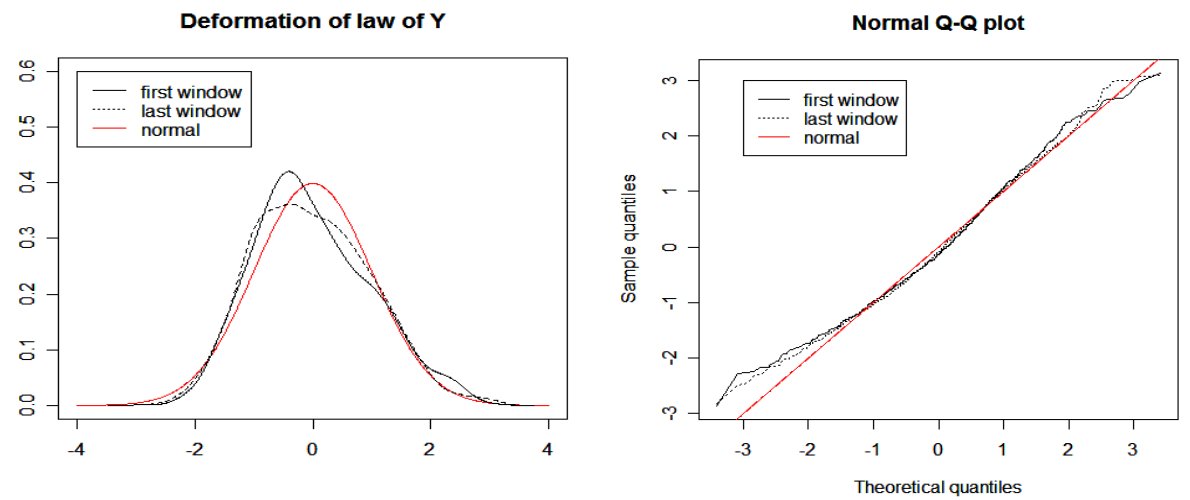